\title{
Skin Immunology and Rejection in VCA and Organ Transplantation
}

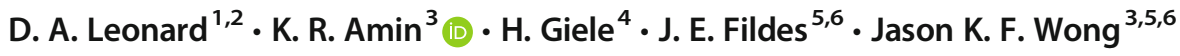

Accepted: 23 October 2020 / Published online: 11 November 2020

(C) The Author(s) 2020

\begin{abstract}
Purpose of Review Skin provides a window into the health of an individual. Using transplanted skin as a monitor can provide a powerful tool for surveillance of rejection in a transplant. The purpose of this review is to provide relevant background to the role of skin in vascularized transplantation medicine.

Recent Findings Discrete populations of T memory cells provide distributed immune protection in skin, and cycle between skin, lymph nodes, and blood. Skin-resident $\mathrm{T}_{\mathrm{REG}}$ cells proliferate in response to inflammation and contribute to long-term VCA survival in small animal models. Early clinical studies show sentinel flap rejection to correlate well with facial VCA skin rejection, and abdominal wall rejection demonstrates concordance with visceral rejection, but further studies are required.

Summary This review focuses on the immunology of skin, skin rejection in vascularized composite allografts, and the recent advances in monitoring the health of transplanted tissues using distant "sentinel" flaps.
\end{abstract}

Keywords Skin $\cdot$ Sentinel skin flaps $\cdot$ Immunology $\cdot$ Vascularized composite allotransplantation $\cdot$ VCA

\section{Introduction}

Vascularized composite allotransplantation (VCA) has become an established option for the restoration of form and function following complex injury or when specialized functional tissues are devitalized. This applies for highly selected cases where conventional, autologous techniques are insufficient to meet such reconstructive requirements. When

This article is part of the Topical Collection on Vascularized Composite Allografts

Jason K. F. Wong

Jason.k.wong@manchester.ac.uk

1 Canniesburn Plastic Surgery Unit, Glasgow Royal Infirmary, Glasgow, UK

2 Institute of Molecular, Cell and Systems Biology, University of Glasgow, Glasgow, UK

3 Department of Plastic and Reconstructive Surgery, Manchester University NHS Foundation Trust, Manchester, UK

4 Nuffield Department of Surgery, Oxford Biomedical Research Centre, University of Oxford, Oxford, UK

5 Division of Cell Matrix Biology and Regenerative Medicine, Blond McIndoe Laboratories, University of Manchester, 3.104 Stopford Building, Oxford Road, Manchester M13 9TP, UK

6 The Transplant Centre, Manchester University NHS Foundation Trust, Manchester, UK compared to solid organ transplantation (SOT), VCA recipients can expect to experience a higher incidence of acute rejection, with approximately $85 \%$ experiencing one or more episodes during their first post-transplant year [1]. The primary site of VCA acute rejection is most often the skin [2], which is highly immunogenic and susceptible to recipient immune responses, compared to other VCA tissues (historically skin transplantation has been used as a rigorous challenge for immunosuppressive or transplant tolerance protocols [3]). The aggressive immune responses against skin have variously been attributed to the mode of transplantation (typically as skin grafts, which undergo secondary revascularization following a period of ischemia), the presence of putative skinspecific antigens, and the role of skin as a barrier organ, containing numerous immunologically active cells and extracellular components [4-6]. However, none of these hypotheses has uniform support in the literature, and in recent years, there has been increasing appreciation of the skin as an immune organ in its own right, housing a complex network of immune cells and processes [7].

While the potential for false negatives (where the skin appears rejection-free, but another tissue is affected) is recognized (albeit poorly defined), clinical observation of skin is utilized as a core component of monitoring in all VCAs with an exposed skin component. Indeed, there is increasing interest in exploring the use of sentinel flaps to provide an 
immunological window for monitoring of solid organ transplants [8]. The aim of this review is to provide an update on skin immunology in the context of VCA rejection, monitoring of transplant health and to identify outstanding questions pertinent to an improved understanding of this unique and visible transplant component.

\section{Skin Immunology}

The skin has historically been recognized as highly immunogenic [9]. Indeed, Murray's early work at the interface of transplantation and reconstructive surgery solidified the immunological preeminence of skin in the hierarchy of tissues [3]. However, other studies have challenged this position and explored various hypotheses for the differential rejection of tissues, including differences in the mode of immune presentation between primarily vascularized transplants and conventional skin grafts, which experience a prolonged period of ischemia and a non-specific inflammatory response that provides a hostile milieu for presentation of alloantigen.

Despite some findings to the contrary in animal models $[10,11]$, and reports of acute rejection targeted to other tissues including mucosa [12] and muscle (unpublished data) in the absence of clinically detectable skin rejection, the literature is broadly supportive of skin as a common target of acute rejection in both experimental and clinical settings. Focusing our discussion on the primarily vascularized skin component of VCAs (in contrast to the experimental transplantation of conventional skin grafts), we should then consider which factors intrinsic to skin might contribute to its immunogenicity. Historically, much discussion has focused on skin-specific antigens as potentially responsible for the susceptibility of the skin to rejection, but the evidence for this has been mixed. Indeed, the true tissue specificity of many of the candidate antigens has frequently been challenged [6].

The concept of skin hosting a specific immune system, as opposed to purely serving as a site of effector function for the central immune system, was popularized as early as the 1980s [13] but gained momentum with Clark's enumeration of the T cell population found within normal human skin (demonstrating the presence of some $1 \times 10^{6} \mathrm{~T}$ cells $/ \mathrm{cm}^{2}$, equivalent to twice the circulating blood-borne population) $[14,15]$. T cells isolated from skin were found to express the skin-homing addressins CCR4 and CLA, and the majority lacked expression of CD62L and CCR7, identifying them as T-effector memory $\left(\mathrm{T}_{\mathrm{EM}}\right)$ cells, capable of recirculation between skin and blood, but not equipped to enter lymph nodes. Interestingly, this study also identified a population of $\mathrm{CLA}^{+}$ T cells which did express CD62L and CCR7 (a minority of the $\mathrm{CLA}^{+}$population in the skin, but $80 \%$ of those found in the blood). These cells share phenotypic markers of both central memory $\left(\mathrm{T}_{\mathrm{CM}}\right)$ and skin homing, suggesting the ability to cycle between the skin and draining lymph nodes. Subsequent studies have further defined skin T cell subtypes, elucidating the presence of four phenotypically and functionally discrete populations of memory $\mathrm{T}$ cells in human skin. Two subtypes remain resident, and two recirculate between skin and circulation. Furthermore, the persistence and distribution of the $\mathrm{T}_{\mathrm{EM}}$ population increase in response to repeated infections to provide an accumulation of regionally distinct immune defense $[16,17 \cdot, 18]$ (Fig. 1a). The presence of a persistent, skin-resident population of $\mathrm{T}_{\mathrm{EM}}$ cells challenges the conventional model of recruitment of $\mathrm{T}_{\mathrm{EM}}$ cells from the circulation into tissues only in response to an inflammatory stimulus. In the context of VCA, taking these findings together with the presence of professional antigen-presenting cells in the epidermis, the potential for a potent response following presentation of alloantigen to resident $T_{\mathrm{EM}}$ cells is clear [19].

The skin-resident $\mathrm{T}$ cell compartment has also been found to include a $5-10 \%$ population of cells with a $\mathrm{T}_{\mathrm{REG}}$ phenotype, expressing high levels of CD25, CD62L, GITR, and FOXP3, in addition to the skin-homing addressins CLA, CCR4, and CCR6 [20, 21]. These cells have demonstrated suppressive function in vitro, both in the context of activation by CD3 and CD28 antibodies and in the presence of IL-15 and dermal fibroblasts, to model chronic skin inflammation. Furthermore, these cells have been found to proliferate in vivo in response to inflammation, downregulating the inflammatory response both locally, and on migration to dermatotrophic lymph nodes [20-24] (Fig. 1b). In the context of transplantation, significantly enhanced $\mathrm{T}_{\text {REG }}$ populations have been found in lymph nodes draining rat hind limb allografts in animals demonstrating long-term allograft survival induced by treatment with an IL-2 fusion protein, antilymphocyte serum, and a 21-day course of cyclosporine A [25]. Skin homing of human $T_{\text {REG }}$ cells, and the role of these cells in preventing skin allograft rejection, has also been demonstrated in humanized mouse systems [26-28]. However, fundamental differences in the immunological milieu of skin grafts in comparison to primarily vascularized skin component of a VCA must be considered when extrapolating from such experiments.

Langerhans cells in the epidermis are well recognized as efficient antigen-presenting cells, but recent studies have attempted to dissect their function in greater detail, identifying potential functional dichotomy, and further highlighting the complexity of immune interactions within the skin. The classical view of these cells as potent stimulators of an effector response is supported by numerous studies, demonstrating a variety of functions (i.e., induction of naïve $\mathrm{CD} 4^{+} \mathrm{T}$ cell differentiation into Th2, Th17, and Th22 phenotypes [29-31], and priming/cross priming of naïve $\mathrm{CD} 8^{+} \mathrm{T}$ cells [32]) (Fig. 1c). In apparent contrast to this, however, corticosteroid exposure has been demonstrated to induce expansion of regulatory $\mathrm{T}$ cells $\left(\mathrm{T}_{\mathrm{REG}}\right.$ ) via upregulation of TGF- $\beta$ by Langerhans cells 


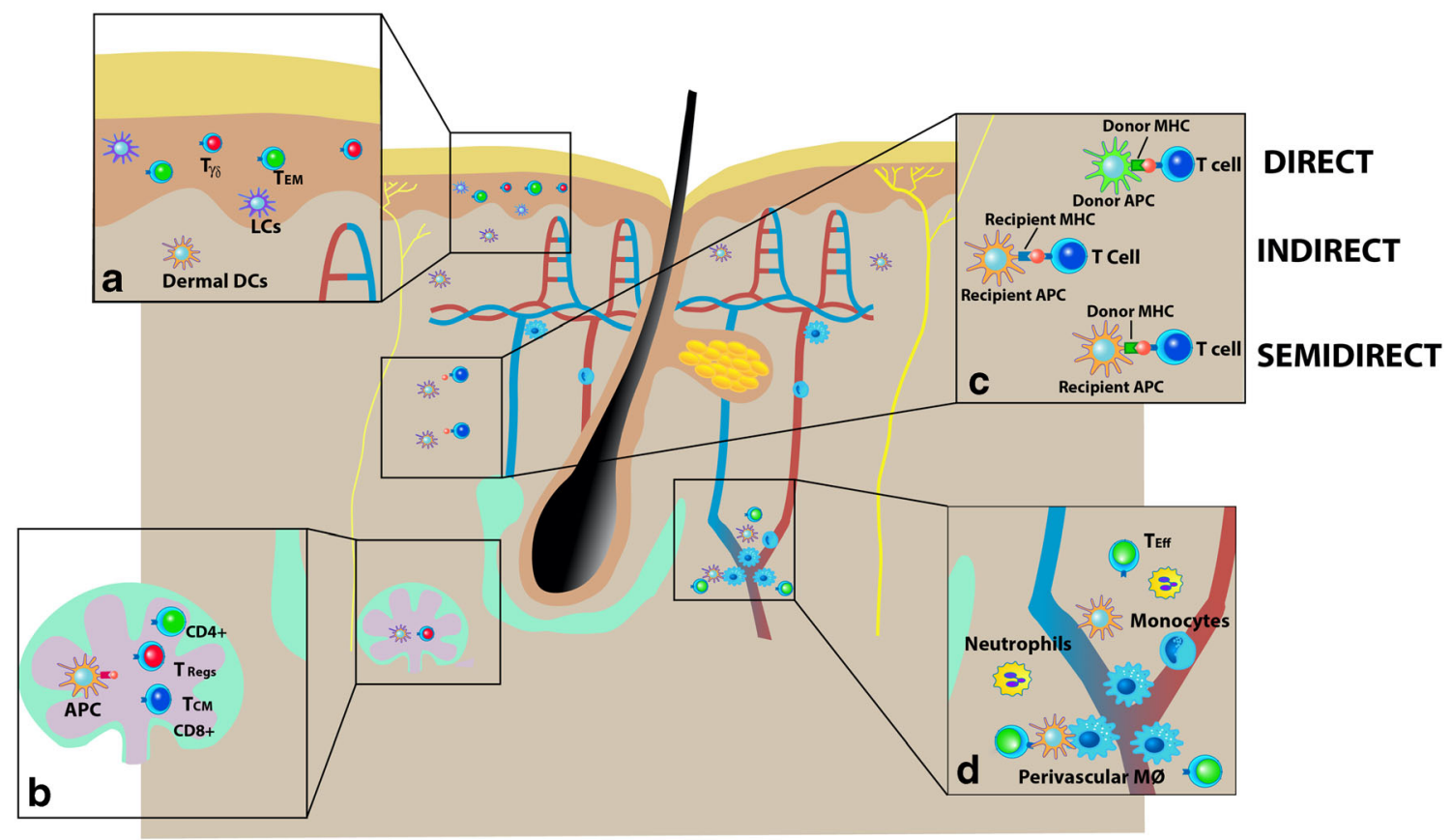

Fig. 1 Immunological role of skin in VCA. a Within the epidermis, below the stratum corneum, Langerhans' cells, Gamma Delta T cells $(T \gamma \delta)$, and resident effector memory $T$ cells $\left(T_{R M}\right)$ reside between the keratinocytes. b Antigen-presenting cells (APC), e.g., Langerhans' cells (LC) and dermal dendritic cells (DC), present donor antigen to naive $\mathrm{T}$ cells and induce the differentiation of $\mathrm{CD}^{+}$and $\mathrm{CD} 8^{+} \mathrm{T}$ cells, including regulatory $\left(\mathrm{T}_{\mathrm{REG}}\right)$ and central memory $\left(\mathrm{T}_{\mathrm{CM}}\right)$ lineages. $\mathrm{T}$ cell populations bearing both skin (CLA, CCR4) and lymph node (CD62L, CCR7) addressin cycle between the skin and dermatotrophic nodes. $\mathbf{c}$ Pathways of allorecognition: direct pathway — donor APC presenting antigen in the

[33]. A potential regulatory role for Langerhans cells is further supported by studies in both murine and human model systems $[34,35]$. While this dichotomy may seem counterintuitive, it suggests that Langerhans cells may play a more nuanced role as regulators of immune homeostasis in the skin, a hypothesis supported by the demonstration that these cells selectively induce activation and proliferation of skinresident $T_{\text {REG }}$ cells at a steady state but, following exposure to pathogen, induce $\mathrm{T}_{\mathrm{EM}}$ proliferation [36].

Applying these insights into the populations of cells and interactions that constitute the immune system of the skin to reconstructive transplantation, the immigration of recipient cells into the transplanted skin, and the emigration of donor cells into the recipient circulation and lymphatic system should be considered. In porcine experimental work, the VCA releases billions of donor leukocytes into the recipient circulation within minutes of reperfusion, which inevitably will contribute to direct presentation of alloantigens [37•]. Recipient dendritic cells have been identified in VCAs in the early stages of acute rejection, a finding which is in marked contrast to the rejection of conventional skin grafts, presumably reflecting the potential for rapid homing of recipient immune cells by translocation from intact vascular channels [38]. context of donor MHC interacts with a recipient $\mathrm{T}$ cell. Indirect pathway-recipient APC presenting donor antigen in the context of recipient $\mathrm{MHC}$ to the recipient $\mathrm{T}$ cell. Semidirect pathway-recipient APC cross-dressed with donor MHC presenting donor antigen to the recipient $\mathrm{T}$ cell. $\mathbf{d}$ Post capillary venules are the site of inducible skinassociated lymphoid tissue (iSALT) where perivascular macrophages and $\mathrm{T}$ cells interact to increase hyperpermeability in the skin, allowing for extravasation and migration of other inflammatory cells such as neutrophils

Indeed, this is supported by the characteristic initial appearance of infiltrates around the vascular bed in the earliest stages of VCA rejection (Fig. 1d) [39].

Current studies using flow cytometric analysis of cells isolated from VCA skin biopsies have identified the co-existence of donor and recipient $\mathrm{T}$ cells within VCA dermis up to 1 year post-transplant. Intriguingly, this includes a well-defined population of recipient $\mathrm{T}$ cells in the absence of any clinical or histological evidence of rejection [40]. These findings are consistent with the well-appreciated risk of aggressive acute rejection stimulated by direct presentation in the early posttransplant phase, diminishing over time with progressive loss of donor APCs, but challenge the conventional expectation that the simple presence of recipient $T$ cells within a transplanted tissue equates with rejection.

\section{Acute Rejection in Vascularized Composite Allografts}

Acute rejection is the most common complication encountered in VCA, with an incidence which continues to remains in the region of $85 \%$ [41]. This substantially exceeds the 
incidence reported for solid organ transplants, but considering the low rate of VCA loss to acute rejection in compliant patients, it is hypothesized that this is, at least in part, due to the ready visibility of skin for clinical monitoring. The appearance of visible changes consistent with rejection triggers an early biopsy and prompt therapy, typically with a steroid bolus and optimization of maintenance therapy. Outside of VCA, this also highlights the potential use of synchronously transplanted donor skin as a sentinel tool to rapidly diagnose rejection of a solid organ transplant.

The chief clinical manifestations of acute rejection are typically a maculopapular erythematous rash, which may be accompanied by edema and induration. In upper limb transplants, typical and atypical patterns have been described, with the former comprising a variable rash mainly distributed over the dorsum of the hand and forearm. The atypical pattern, which has been associated with repetitive microtrauma in patients who resume manual work or are dependent on their hands for mobility, presents with palmar papules, scaling, and lichenification, in combination with dystrophic changes to the nail complexes [41-43].

The histological appearances of acute skin rejection are somewhat lacking in specificity, particularly in the early stages, when the predominant feature is often a sparse perivascular lymphocytic infiltrate. With increasing severity, these infiltrates become more dense, and expand to involve the adnexae, particularly hair follicles and the epidermis. Epidermal apoptosis is pathognomic for Banff grade 3 rejection, with grade 4 characterized by frank necrosis [2] (Fig. 2).
Vascular injury is not included within the current Banff system but has been recognized in both experimental and clinical specimens at the higher rejection grades [44-46]. Similarly, the current grading system and the majority of the literature focus on features of acute cellular rejection, and relatively, little work has focused on antibody-mediated rejection (AMR), not least due to the scarcity with which it has been diagnosed and the absence of a clear correlation between $\mathrm{C} 4 \mathrm{~d}$ deposition and donor-specific antibody (DSA) formation in VCA [12, 47, 48].

While skin is typically considered the primary site of acute rejection in VCA, there have been notable reports to the contrary. Rejection of the mucosal component of facial allografts has been found to both precede and exceed cutaneous involvement in severity [12, 39, 47, 49]. Furthermore, histological signs of rejection have been observed in deep tissue biopsies in the context of clinically normal skin appearances, with grade 0 or 1 rejection on skin biopsy [50]. Taken together, these reports highlight the importance of a high index of suspicion and a low threshold for biopsy in the management of suspected acute rejection post-VCA.

\section{Chronic Rejection in Vascularized Composite Allografts}

Chronic rejection describes a process of progressive functional deterioration, mediated by immune and potentially nonimmune mechanisms, and is the predominant cause of late
Fig. 2 Illustration of Banff classification of VCA skin rejection. a Grade 1: Mild perivascular/dermal infiltration (arrow). No involvement of the overlying epidermis. b Grade 2 Moderatetosevere perivascular inflammation (arrow) with or without mild epidermal and/ or adnexal involvement (limited to spongiosis and exocytosis). No epidermal dyskeratosis or apoptosis. c Grade 3: Dense inflammation and epidermal involvement with epithelial apoptosis, dyskeratosis, and/or keratinolysis (arrows). d Grade 4: Necrotizing acute rejection. Frank necrosis of epidermis or other skin structures (arrow)
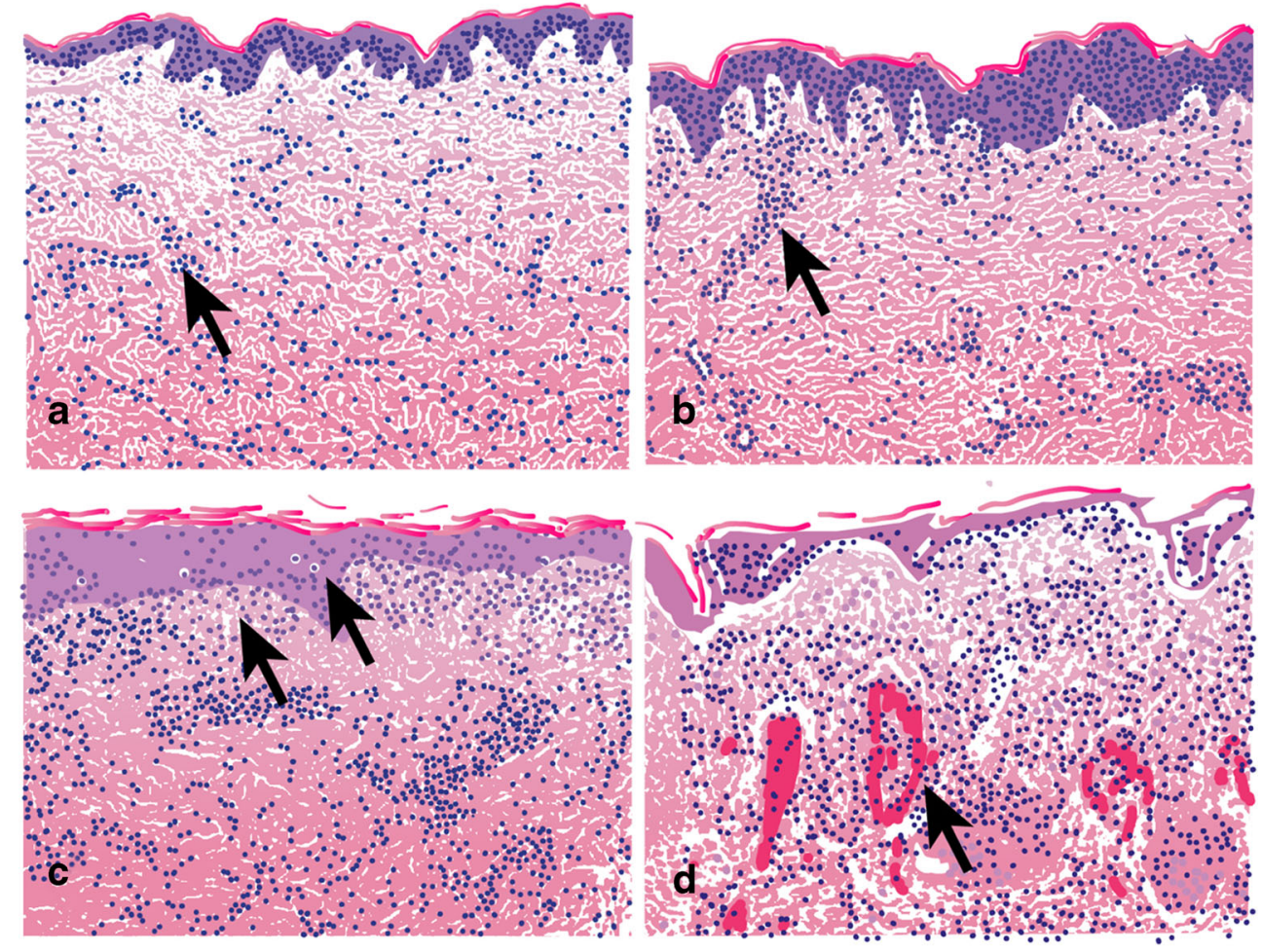
graft loss in SOT $[51,52]$. In renal and cardiac transplants, AMR is implicated as a key mechanism, with damage to transplant vascular endothelium mediated by DSA. This occurs classically, albeit not solely, via complement-dependent pathways as evidenced by endothelial deposition of C4d [53, 54]. Downstream pathways result in arteriopathy, characterized by intimal hyperplasia, fibrosis, and ultimately ischemic necrosis [55].

As yet, a consensus definition of chronic rejection has not been established for VCA, though clinical and pathological features have been observed in an increasing number of cases as we enter the third decade of clinical experience in this field. VCA chronic rejection appears to primarily target the skin and vasculature. Cutaneous features include psoriasiform plaques, purpuric rashes, sclerosis, dyschromia, and necrotic ulcers [39, 56, 57] (Fig. 3).

Pathologically, the most marked feature has been vasculopathy, with prominent myointimal proliferation and luminal narrowing. This has been observed in both moderate cutaneous and deep vessels and is associated with progressive ischemic degradation of the transplant $[50,58]$. Additional microscopic features have included adnexal atrophy, basal cell vacuolation, and melanin incontinence, while cellular infiltration (including both $\mathrm{CD} 4+\mathrm{T}$ cells, and $\mathrm{CD} 20+\mathrm{B}$ cells) and $\mathrm{C} 4 \mathrm{~d}$ deposition have been reported in some cases, but not uniformly [59]. Additional features potentially correlating with chronic rejection include the formation of tertiary lymphoid organs (TLO) composed of dermal lymphoid aggregates in association with C4d-positive high endothelial venule-like vessels, the appearances of which are reminiscent of lymphoid follicles occurring during chronic rejection of SOTs [60, 61]. Interestingly, dermal capillary thrombosis has been identified as a feature of severe acute VCA rejection, which may predict the development of features of chronic rejection [58].

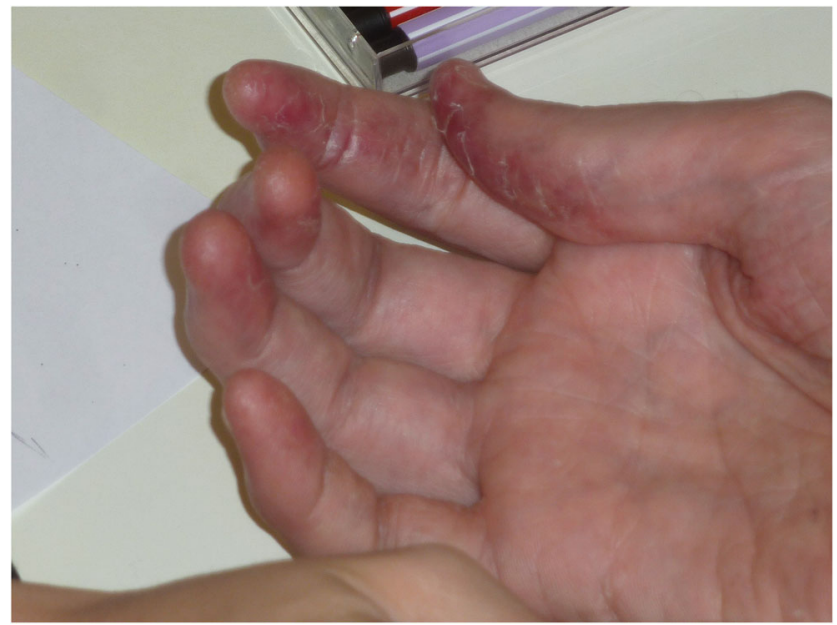

Fig. 3 Features of chronic rejection in a hand transplant. Sclerosis, dyschromia/ purpuric rash, and lichenification on the fingertips of a hand transplant. These features, suggestive of chronic rejection, appeared 10 years post-transplant
Consistent with the currently incomplete clinical picture and absence of a concise clinicopathological definition for chronic rejection in VCA, the pathological mechanisms are incompletely understood. Certainly, cases have been associated with inadequate immunosuppression (either as a result of non-compliance, or necessitated by management of infectious or neoplastic complications), but this is not universally the case. In keeping with SOT, an immunologically quiescent early post-transplant course does not preclude development of chronic rejection $[50,56,58]$. Extrapolating from SOT, it would be expected that a combination of immune (chiefly AMR), and non-immune mechanisms including ischemiareperfusion injury, drug toxicity, and transplant vascular resistance may be implicated. Unfortunately, as experience in this field extends, increasing numbers of patients are presenting with features of chronic rejection, for which current therapeutic options are extremely limited. Detailed reporting and collaborative investigation of the mechanisms underlying these changes will be invaluable.

\section{Clinical Grading of VCA Rejection}

Routine assessment of skin containing VCAs chiefly comprises of visual inspection and histologic inspection of skin biopsies. The salient clinical and histopathological features of acute rejection have been described and correlated with comparable findings in experimental models [39, 62, 63]. These observations formed the basis of the Banff Working Classification for VCA rejection, which provided an overall grading system, and which has facilitated reporting and interinstitutional collaboration [44, 64].

The four Banff grades, which are based on combinations of perivascular and epidermal infiltration, and evidence of epidermal injury, are summarized in Fig. 2. While the current Banff classification does provide a standardized system for grading of VCA rejection, and a valuable framework for data reporting by VCA centers, the variables are not independently scored. There is no assessment of vascular inflammation, or features of chronic allograft vasculopathy, both of which could yield insights into variations in the pattern and pathogenesis of rejection. Indeed, the benefits of a systematic approach to the assessment of VCA histopathology have been acknowledged at recent international workshops, and collaborative efforts to develop systematic scoring systems, akin to those in routine use for assessment of renal transplant biopsies, for instance, are ongoing [45, 65].

Conventional histological grading is frequently augmented by immunohistochemical techniques in the VCA literature, and while such methods are not currently included in the grading system, they can offer additional insights into mechanism and pathogenesis. To this end, other groups have introduced techniques for cellular and molecular level analysis of 
skin rejection, but these are yet to achieve widespread application or independent validation [66].

\section{Sentinel Skin Flaps in VCA}

The early identification and treatment of graft rejection may be important for long-term structural and functional outcomes following VCA [67]. This concern, paired with a desire to avoid any additional burden of scarring to the visible components of reconstructive transplants, such as the face or hands, prompted application of additional distant transplants of donor skin for monitoring and biopsy purposes. While conventional skin grafts were utilized for monitoring rejection in some early hand transplants, this practice was abandoned when it was observed that such grafts lost their monitoring potential over time, with fundamental differences in cell trafficking and immune response with the mode of vascularization $[68,69]$.

Vascularized sentinel flaps have been utilized for some face transplants. These have typically been transplanted to a discrete anatomical location, such as the inframammary fold, or in some cases, provided additional utility in the release of limb contractures $[62,70]$. In the small number of cases reported, concordance between the sentinel flap and index transplant skin has been generally good, with an analysis of paired biopsies demonstrating an overall correlation coefficient of 0.88 , with a trend towards greater concordance at the higher grades of rejection (100\% for Banff grade III) [70]. However, there may be discordance between rejection of skin and other tissues, such as mucosa [62], and further clarification of the clinical value of this approach is required.

\section{Sentinel Skin Flaps in Solid Organ Transplantation}

Recognition of the susceptibility of the skin to acute rejection, and its accessibility for clinical monitoring, has prompted consideration of the broader utilization of transplanted skin for "sentinel" monitoring of the health of solid organ transplants. This is of potential benefit when reliable and timely diagnosis of rejection is challenging, and the process of obtaining diagnostic biopsies is not without risk to both the transplant and patient [71-74]. Perhaps the most obvious question, given the absence of a skin component within solid organs, is to what extent rejection of sentinel skin will be concordant with rejection of the transplanted organ?

Some data can be extrapolated from intestinal or multivisceral transplantation in combination with abdominal wall transplantation, for cases with complex abdominal wall defects and loss of abdominal domain (Fig. 4). These cases, of which over 50 have been reported to date, indicate that abdominal wall skin could be an indicator of visceral rejection,

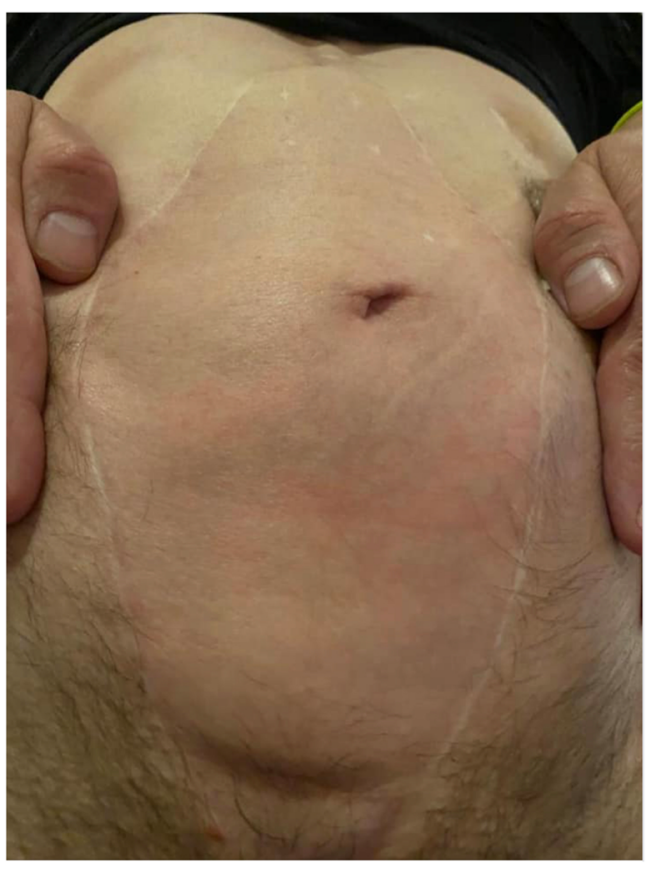

Fig. 4 Abdominal wall transplant at 2 years post-transplant. Clinical photograph of abdominal wall transplant performed in combination with a modified multi-visceral intestinal transplant, for which it also serves as a sentinel monitor

and that cutaneous rejection may manifest earlier than visceral rejection, providing a useful therapeutic opportunity [8]. In addition, intestinal transplant patients presenting with posttransplant bowel dysfunction, in the absence of abdominal wall skin rejection for whom the most likely differential diagnosis is infective enteritis, have been spared damaging escalation of immunosuppression [75]. Indeed, data from the Oxford group demonstrate statistically significant advantages in intestinal transplant survival (79\% vs 60\%), intestinal rejection rate (7\% vs $27 \%$ ), and misdiagnosis of infection as rejection (14\% vs $33 \%$ ) in patients receiving organ transplant plus abdominal wall $(n=13)$ in comparison to those receiving organ transplant alone $(n=15)$ [76•]. On a cautionary note, episodes of discordant skin and intestinal rejection have been reported, but in almost all of these cases, metachronous transplantation of abdominal wall and viscera were performed from separate donors, and in the context of sentinel monitoring, this practice would not be advised [77].

The encouraging results from patients undergoing combined visceral and abdominal wall transplants, and the high levels of concordant rejection between sentinel and primary VCAs, suggest a potential benefit of sentinel monitoring to patients undergoing solid organ transplantation, where monitoring is challenging, and the consequences of missed rejection episodes or misdiagnosis are high. Procurement of a fasciocutaneous flap (such as the radial forearm, or posterior tibial artery flaps) from the organ donor and its transplant to a suitable location (Fig. 5) are relatively straightforward 
procedures, which can be performed without interference with the organ transplant teams [78]. Early concerns that transplantation of skin might pose an additional immunological challenge to the patient and necessitate higher levels of immunosuppression have not been borne out, but to date, the experience in this area is limited to observational studies in relatively small numbers of patients. The outcome of clinical trials specifically designed to assess the efficacy and safety of sentinel skin monitoring of solid organ transplants, such as those underway in Oxford, is keenly awaited.

\section{Conclusions}

Uniquely in the field of transplant surgery, VCA includes an externalized component, the skin, which is readily available for clinical monitoring (including biopsy), with minimal inconvenience or morbidity for the patient. This is in marked contrast to all forms of SOT, where diagnosis of rejection is frequently delayed, and carries the potential for biopsy induced morbidity. This contrast likely contributes to the unique combination of a high frequency of acute rejection episodes but low incidence of graft loss (to acute rejection) that characterizes VCA.

Our understanding of the complex immunobiology of skin has expanded steadily in recent years, and these insights are gradually translating into transplantation. Similarly, the potential that sentinel skin flaps may have utility in the monitoring of SOTs for rejection is a fascinating corollary to reconstructive transplantation, which if proven could dramatically alter

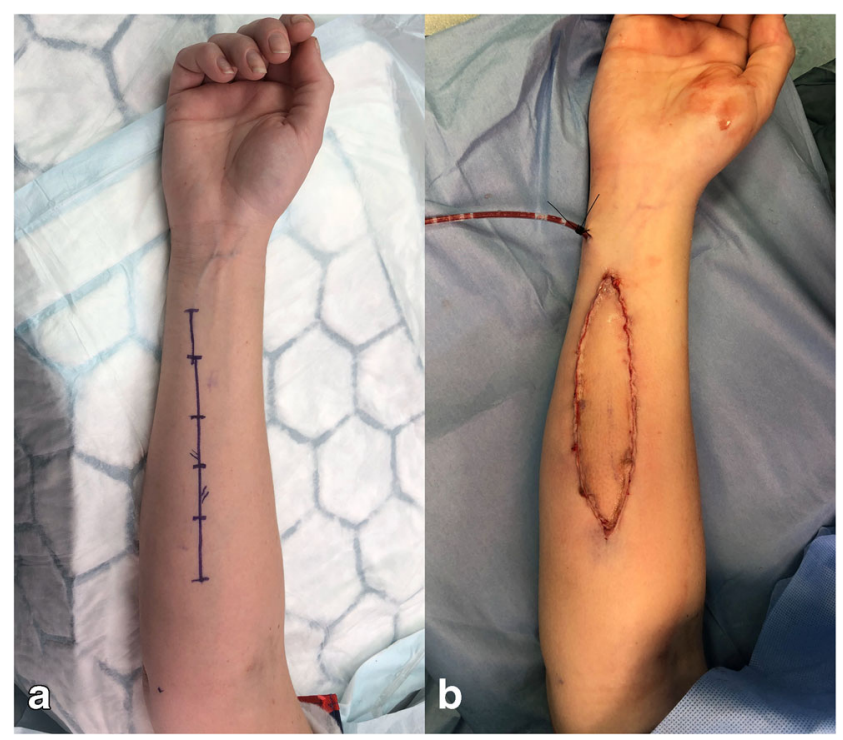

Fig. 5 Sentinel flap for SOT monitoring. a Forearm markings for the incision to inset sentinel forearm flap onto ulnar artery. b Sentinel flap in situ the management of SOT recipients. Such a step would increase the number of patients receiving skin bearing VCAs, substantially increasing the rate at which clinical data is accumulated in this field.

The continued efforts to unravel the pathogenesis of skin rejection, and in particular chronic rejection, will only be of increasing significance as the stance of reconstructive transplantation becomes clearer longer term. This will undoubtedly require continued detailed reporting and ideally, given the relatively small numbers of patients cared for by any individual VCA center, open international collaboration to address these challenging questions.

\section{Compliance with Ethical Standards}

Conflict of Interest The authors declare that they have no conflict of interest

Open Access This article is licensed under a Creative Commons Attribution 4.0 International License, which permits use, sharing, adaptation, distribution and reproduction in any medium or format, as long as you give appropriate credit to the original author(s) and the source, provide a link to the Creative Commons licence, and indicate if changes were made. The images or other third party material in this article are included in the article's Creative Commons licence, unless indicated otherwise in a credit line to the material. If material is not included in the article's Creative Commons licence and your intended use is not permitted by statutory regulation or exceeds the permitted use, you will need to obtain permission directly from the copyright holder. To view a copy of this licence, visit http://creativecommons.org/licenses/by/4.0/.

\section{References}

Papers of particular interest, published recently, have been highlighted as:

- Of importance

1. Petruzzo P, Lanzetta M, Dubernard JM, Landin L, Cavadas P, Margreiter R, et al. The international registry on hand and composite tissue transplantation. Transplantation. 2010;90:1590-4.

2. Hautz T, Zelger BG, Weissenbacher A, Zelger B, Brandacher G, Landin L, et al. Standardizing skin biopsy sampling to assess rejection in vascularized composite allotransplantation. Clin Transpl. 2013;27:E81-90.

3. Murray JE. Organ transplantation (skin, kidney, heart) and the plastic surgeon. Plast Reconstr Surg. 1971;47:425-31.

4. Medawar PB. The behaviour and fate of skin autografts and skin homografts in rabbits: a report to the War Wounds Committee of the Medical Research Council. J Anat. 1944;78:176-99.

5. Steinmuller D, Lofgreen JS. Differential survival of skin and heart allografts in radiation chimaeras provides further evidence for Sk histocompatibility antigen. Nature. 1974;248:796-7.

6. Steinmuller D. The enigma of skin allograft rejection. Transplant Rev. 1998;12:42-57.

7. Clark RA. Skin-Resident T cells: the ups and downs of on site immunity. J Invest Dermatol. 2009;130:362-70. 
8. Ali JM, Catarino P, Dunning J, Giele H, Vrakas G, Parmar J. Could sentinel Skin transplants have some utility in solid organ transplantation? Transplant Proc. 2016;48:2565-70.

9. Medawar PB. Relationship between the antigens of blood and skin. Nature. 1946;157:161-2.

10. Lee WP, Yaremchuk MJ, Pan YC, Randolph MA, Tan CM, Weiland AJ. Relative antigenicity of components of a vascularized limb allograft. Plast Reconstr Surg. 1991;87:401-11.

11. Jones ND, Turvey SE, Van Maurik A, Hara M, Kingsley CI, Smith $\mathrm{CH}$, et al. Differential susceptibility of heart, skin, and islet allografts to T cell-mediated rejection. J Immunol. 2001;166: 2824-30.

12. Fischer S, Lian CG, Kueckelhaus M, Strom TB, Edelman ER, Clark RA, et al. Acute rejection in vascularized composite allotransplantation. Curr Opin Organ Transplant. 2014;19:531-44.

13. Streilein JW. Skin-associated lymphoid tissues (SALT): origins and functions. J Invest Dermatol. 1983;80:12-7.

14. Bos JD, Zonneveld I, Das PK, Krieg SR, van der Loos CM, Kapsenberg ML. The skin immune system (SIS): distribution and immunophenotype of lymphocyte subpopulations in normal human skin. J Invest Dermatol. 1987;88:569-73.

15. Clark RA, Chong B, Mirchandani N, Brinster NK, Yamanaka K-I, Dowgiert RK, et al. The vast majority of CLA+ T cells are resident in normal skin. J Immunol. 2006;176:4431-9.

16. Clark RA, Watanabe R, Teague JE, Schlapbach C, Tawa MC, Adams N, et al. Skin effector memory T cells do not recirculate and provide immune protection in alemtuzumab-treated CTCL patients. Sci Transl Med. 2012;4:117ra7.

17. Watanabe R, Gehad A, Yang C, Scott LL, Teague JE, Schlapbach C, et al. Human skin is protected by four functionally and phenotypically discrete populations of resident and recirculating memory T cells. Sci Transl Med. 2015;7:279ra39 Demonstrates the presence of two resident and two recirculating $T$ cell populations in human skin, with distinct territories of migration and functional capacity.

18. Jiang X, Clark RA, Liu L, Wagers AJ, Fuhlbrigge RC, Kupper TS. Skin infection generates non-migratory memory CD8+ TRM cells providing global skin immunity. Nature. 2012;483:1-6.

19. Stingl G, Katz SI, Clement L, Green I, Shevach EM. Immunologic functions of Ia-bearing epidermal Langerhans cells. J Immunol. 1978;121:2005-13.

20. Clark RA, Kupper TS. IL-15 and dermal fibroblasts induce proliferation of natural regulatory $\mathrm{T}$ cells isolated from human skin. Blood. 2007;109:194-202 Available from:.

21. Clark RA, Huang SJ, Murphy GF, Mollet IG, Hijnen D, Muthukuru $\mathrm{M}$, et al. Human squamous cell carcinomas evade the immune response by down-regulation of vascular E-selectin and recruitment of regulatory T cells. J Exp Med. 2008;205:2221-34.

22. Vukmanovic-Stejic M, Agius E, Booth N, Dunne PJ, Lacy KE, Reed JR, et al. The kinetics of CD4+Foxp3+ T cell accumulation during a human cutaneous antigen-specific memory response in vivo. J Clin Invest. 2008;118:3639-50.

23. Dudda JC, Perdue N, Bachtanian E, Campbell DJ. Foxp3+ regulatory $\mathrm{T}$ cells maintain immune homeostasis in the skin. J Exp Med. 2008;205:1559-65.

24. Tadokoro CE, Shakhar G, Shen S, Ding Y, Lino AC, Maraver A, et al. Regulatory $\mathrm{T}$ cells inhibit stable contacts between CD4+ T cells and dendritic cells in vivo. J Exp Med. 2006;203:505-11.

25. Jindal R, Unadkat J, Zhang W, Zhang D, Ng TW, Wang Y, et al. Spontaneous resolution of acute rejection and tolerance induction with IL-2 fusion protein in vascularized composite allotransplantation. Am J Transplant. 2015;15:1231-40.

26. Issa F, Hester J, Goto R, Nadig SN, Goodacre TE, Wood K. Ex vivo-expanded human regulatory $\mathrm{T}$ cells prevent the rejection of skin allografts in a humanized mouse model. Transplantation. 2010;90:1321-7.
27. Issa F, Hester J, Milward K, Wood KJ. Homing of regulatory T cells to human skin is important for the prevention of alloimmunemediated pathology in an in vivo cellular therapy model. PLoS One. 2012;7:e53331.

28. Sagoo P, Ali N, Garg G, Nestle FO, Lechler RI, Lombardi G. Human regulatory $\mathrm{T}$ cells with alloantigen specificity are more potent inhibitors of alloimmune skin graft damage than polyclonal regulatory T cells. Sci Transl Med. 2011;3:83ra42.

29. Furio L, Briotet I, Journeaux A, Billard H, Péguet-Navarro J. Human Langerhans cells are more efficient than CD14-CD1c+ dermal dendritic cells at priming naive CD4+ T cells. J Invest Dermatol. 2010;130:1345-54.

30. Fujita H, Nograles KE, Kikuchi T, Gonzalez J, Carucci JA, Krueger JG. Human Langerhans cells induce distinct IL-22-producing CD4+ T cells lacking IL-17 production. Proc Natl Acad Sci U S A. 2009;106:21795-800.

31. Mathers AR, Janelsins BM, Rubin JP, Tkacheva OA, Shufesky WJ, Watkins SC, et al. Differential capability of human cutaneous dendritic cell subsets to initiate Th17 responses. J Immunol. 2009;182: 921-33.

32. Klechevsky E, Morita R, Liu M, Cao Y, Coquery S, ThompsonSnipes L, et al. Functional specializations of human epidermal Langerhans cells and CD14+ dermal dendritic cells. Immunity. 2008;29:497-510.

33. Stary G, Klein I, Bauer W, Koszik F, Reininger B, Kohlhofer S, et al. Glucocorticosteroids modify Langerhans cells to produce TGF- $\beta$ and expand regulatory T cells. J Immunol. 2010;186:10312.

34. Kaplan DH, Jenison MC, Saeland S, Shlomchik WD, Shlomchik MJ. Epidermal langerhans cell-deficient mice develop enhanced contact hypersensitivity. Immunity. 2005;23:611-20.

35. van der Aar AMG, Picavet DI, Muller FJ, de Boer L, van Capel TMM, Zaat SAJ, et al. Langerhans cells favor skin flora tolerance through limited presentation of bacterial antigens and induction of regulatory T cells. J Invest Dermatol. 2013;133:1240-9.

36. Seneschal J, Clark RA, Gehad A, Baecher-Allan CM, Kupper TS. Human epidermal Langerhans cells maintain immune homeostasis in skin by activating skin resident regulatory $\mathrm{T}$ cells. Immunity. 2012;36:873-84.

37. Amin KR, Ball AL, Chhina C, Edge RJ, Stone JP, Critchley WR, et al. Ex-vivo flush of the limb allograft reduces inflammatory burden prior to transplantation. J Plast Reconstr Aesthet Surg. 2018;71:140-6 Quantifies the burden of passenger leukocytes and inflammatory debris associated with limb transplant in an ex vivo large animal model, and the reduction of this burden by isotonic post-preservation flush.

38. Zamfirescu DG, Owen E, Lascar I, Molitor M, Zegrea I, Popescu $\mathrm{M}$, et al. Sentinel skin allograft — a reliable marker for monitoring of composite tissue transplant rejection. Transplant Proc. 2009;41: 503-8.

39. Kanitakis J, Jullien D, Petruzzo P, Hakim N, Claudy A, Revillard J$\mathrm{P}$, et al. Clinicopathologic features of graft rejection of the first human hand allograft. Transplantation. 2003;76:688-93.

40. Leonard DA, Powell HR, Defazio MW, Shanmugarajah K, Mastroianni M, Rosales IA, et al. Cutaneous leukocyte lineages in tolerant large animal and immunosuppressed clinical vascularised composite allograft recipients. Am J Transplant 2020. https://doi.org/10.1111/ajt.16230.

41. Kueckelhaus M, Fischer S, Seyda M, Bueno EM, Aycart MA, Alhefzi M, et al. Vascularized composite allotransplantation: current standards and novel approaches to prevent acute rejection and chronic allograft deterioration. Transpl Int. 2015;29:655-62.

42. Etra JW, Shores JT, Sander IB, Brandacher G, Lee WPA. Traumainduced rejection in vascularized composite allotransplantation. Ann Surg. 2020;271:e113-4. 
43. Sarhane KA, Tuffaha SH, Broyles JM, Ibrahim AE, Khalifian S, Baltodano $\mathrm{P}$, et al. A critical analysis of rejection in vascularized composite allotransplantation: clinical, cellular and molecular aspects, current challenges, and novel concepts. Front Immunol. 2013;4:406.

44. Cendales LC, Kanitakis J, Schneeberger S, Burns C, Ruiz P, Landin $\mathrm{L}$, et al. The Banff 2007 working classification of skin-containing composite tissue allograft pathology. Am J Transplant. 2008;8: 1396-400.

45. Rosales IA, Foreman RK, DeFazio M, Sachs DH, Curtis L, Cetrulo $\mathrm{J}$, et al. Systematic pathological component scores for skincontaining vascularized composite allografts. Vasc Compos Allotransplantation. 2017;0:1-13.

46. Lian CG, Bueno EM, Granter SR, Laga AC, Saavedra AP, Lin WM, et al. Biomarker evaluation of face transplant rejection: association of donor $\mathrm{T}$ cells with target cell injury. Mod Pathol. 2014;27:788-99.

47. Chandraker A, Arscott R, Murphy GF, Lian CG, Bueno EM, Marty FM, et al. The management of antibody-mediated rejection in the first presensitized recipient of a full-face allotransplant. Am J Transplant. 2014;6:1446-52.

48. Weissenbacher A, Hautz T, Zelger B, Zelger BG, Mayr V, Brandacher G, et al. Antibody-mediated rejection in hand transplantation. Transpl Int. 2014;27:13-7.

49. Lantieri L, Hivelin M, Benjoar M-D, Audard V, Meningaud JP, Bellivier F, et al. Face transplantation outcomes: feasibility, reproducibility and efficacy. Plast Reconstr Surg. 2010;126:126.

50. Kaufman CL, Ouseph R, Blair B, Kutz JE, Tsai TM, Scheker LR, et al. Graft vasculopathy in clinical hand transplantation. Am J Transplant. 2012;12:1004-16.

51. Heemann U, Lutz J. Pathophysiology and treatment options of chronic renal allograft damage. Nephrol Dial Transplant. 2013;28:2438-46.

52. Thaunat O, Badet L, Dubois V, Kanitakis J, Petruzzo P, Morelon E. Immunopathology of rejection: do the rules of solid organ apply to vascularized composite allotransplantation? Curr Opin Organ Transplant. 2015;20:596-601.

53. Abrahimi P, Liu R, Pober JS. Blood vessels in allotransplantation. Am J Transplant. 2015;15:1748-54.

54. Thaunat $\mathrm{O}$. Humoral immunity in chronic allograft rejection: puzzle pieces come together. Transpl Immunol. 2012;26:101-6.

55. Hillebrands J, van den Hurk BM, Klatter FA, Popa ER, Nieuwenhuis P, Rozing J. Recipient origin of neointimal vascular smooth muscle cells in cardiac allografts with transplant arteriosclerosis. J Heart Lung Transplant. 2000;19:1183-92.

56. Kanitakis J, Karayannopoulou G, Lanzetta M, Petruzzo P. Graft vasculopathy in the skin of a human hand allograft: implications for diagnosis of rejection of vascularized composite allografts. Transpl Int. 2014;27:e118-23.

57. Petruzzo P, Kanitakis J, Testelin S, Pialat J-B, Buron F, Badet L, et al. Clinicopathological findings of chronic rejection in a face grafted patient. Transplantation. 2015;99:2644-50.

58. Kanitakis J, Petruzzo P, Gazarian A, Karayannopoulou G, Buron F, Dubois V, et al. Capillary thrombosis in the skin. Transplantation. 2016;100:954-7.

59. Morelon E, Petruzzo P, Kanitakis J. Chronic rejection in vascularized composite allotransplantation. Curr Opin Organ Transplant. 2018;23:582-91.

60. Thaunat O, Field A-C, Dai J, Louedec L, Patey N, Bloch M-F, et al. Lymphoid neogenesis in chronic rejection: evidence for a local humoral alloimmune response. Proc Natl Acad Sci U S A. 2005;102:14723-8.

61. Hautz T, Zelger BG, Nasr IW, Mundinger GS, Barth RN, Rodriguez ED, et al. Lymphoid neogenesis in skin of human hand, nonhuman primate, and rat vascularized composite allografts. Transpl Int. 2014;27:966-76.
62. Kanitakis J, Badet L, Petruzzo P, Béziat JL, Morelon E, Lefrançois $\mathrm{N}$, et al. Clinicopathologic monitoring of the skin and oral mucosa of the first human face allograft: report on the first eight months. Transplantation. 2006;82:1610-5.

63. Zdichavsky M, Jones JW, Ustuner ET, Ren X, Edelstein J, Maldonado C, et al. Scoring of skin rejection in a swine composite tissue allograft model. J Surg Res. 1999;85:1-8.

64. Kanitakis J. The challenge of dermatopathological diagnosis of composite tissue allograft rejection: a review. J Cutan Pathol. 2008:35:738-44.

65. Roufosse C, Simmonds N, Clahsen-van Groningen M, Haas M, Henriksen KJ, Horsfield C, et al. A 2018 reference guide to the Banff classification of renal allograft pathology. Transplantation. 2018;102:1795-814.

66. Oda H, Ikeguchi R, Aoyama T, Ohta S, Noguchi T, Kaizawa Y, et al. Relative antigenicity of components in vascularized composite allotransplants: an experimental study of microRNAs expression in rat hind limb transplantation model. Microsurgery. 2019;39:340-8.

67. Unadkat JV, Schneeberger S, Horibe EH, Goldbach C, Solari MG, Washington KM, et al. Composite tissue vasculopathy and degeneration following multiple episodes of acute rejection in reconstructive transplantation. Am J Transplant. 2010;10:251-61.

68. Lanzetta M, Petruzzo P, Vitale G, Lucchina S, Owen ER, Dubernard JM, et al. Human hand transplantation: what have we learned? Transplant Proc. 2004;36:664-8.

69. Horner BM, Ferguson KK, Randolph MA, Spencer JA, Carlson AL, Hirsh EL, et al. In vivo observations of cell trafficking in allotransplanted vascularized skin flaps and conventional skin grafts. J Plast Reconstr Aesthet Surg. 2010;63:711-9.

70. Kueckelhaus M, Fischer S, Lian CG, Bueno EM, Marty FM, Tullius SG, et al. Utility of sentinel flaps in assessing facial allograft rejection. Plast Reconstr Surg. 2015;135:250-8.

71. Van Ha TG. Liver biopsy in liver transplant recipients. Semin Interv Radiol. 2004;21:271-4.

72. Saraiva F, Matos V, Gonalves L, Antunes M, Providência LA. Complications of endomyocardial biopsy in heart transplant patients: a retrospective study of 2117 consecutive procedures. Transplant Proc. 2011;43:1908-12.

73. Trulock EP, Ettinger NA, Brunt EM, Pasque MK, Kaiser LR, Cooper JD. The role of transbronchial lung biopsy in the treatment of lung transplant recipients; an analysis of 200 consecutive procedures. Chest. 1992;102:1049-54.

74. Plattner BW, Chen P, Cross R, Leavitt MA, Killen PD, Heung M. Complications and adequacy of transplant kidney biopsies: a comparison of techniques. J Vasc Access. 2018;19:291-6.

75. Barnes J, Issa F, Vrakas G, Friend $\mathrm{P}$, Giele $\mathrm{H}$. The abdominal wall transplant as a sentinel skin graft. Curr Opin Organ Transplant. 2016;21:536-40.

76. Gerlach UA, Vrakas G, Sawitzki B, Macedo R, Reddy S, Friend PJ, et al. Abdominal wall transplantation: skin as a sentinel marker for rejection. Am J Transplant. 2016;16:1892-900 Demonstrates the sentinel role of abdominal wall skin, and significant benefits of combined abdominal wall and visceral transplant in intestinal graft survival, intestinal rejection rate, and diagnostic accuracy of intestinal rejection in comparison to visceral transplant alone.

77. Levi DM, Tzakis AG, Kato T, Madariaga J, Mittal NK, Nery J, et al. Transplantation of the abdominal wall. Lancet. 2003;361: 2173-6.

78. Amer H, Suchyta M, Carlsen B, Bakri K, Mardini S. The posterior tibial artery flap as a sentinel flap in face transplant: maximizing solid organ and composite tissue allotransplant team coordination. Transplantation. 2017;101:S50.

Publisher's Note Springer Nature remains neutral with regard to jurisdictional claims in published maps and institutional affiliations. 